\title{
Dagshistorie 1907.
}

Tildragelser vedrørende Nordslesvig, optegnede efter Tidsfglgen.

11. Januar. Konventionen mellem Danmark og Tyskland om Optanthørns Optagelse i det prøjsiske Undersaatsforhold afsluttes. (Jf. Sønderj. Aarb. 1907, S. 177 ff.)

18. Januar. Forsamlingshuset i Tyrsbel tages i Brug.

23. Januar. Forsamlingshuset i Tandslet indvies ved et Valgmøde, hvori der deltager 400 Personer. 25. Januar. Valir til den tyske Rigsdag (Jf. 13. Decbr. 1906). - I 1. Valgkres vælges de danskes Kandidat, Redakter H. P. Hanssen, med 10) 406 Stemmer, medens Tyskernes Kandidat, Landsretsdommer Dr Hahn, faar $5168 \mathrm{og}$ Socialdemokraternes Kandidat, Arbejdersekretær G. Niendorf i Kiel, 784 Stemmer. - I 2. Talgkres afgives der 3236 danske Stemmer paa Gaardejer P. Grau i Pøl og i 4. Talykkres 1783 paa pensioneret Degn og Skolelærer P. Jessen i Sønderborg. - Ialt afgives der i Nordslesvig 15451 danske Stemmer, d. v. s. 594 flere end ved Valget i 1903 .

5. Februar. Ved Omvalget til den tyske Rigsdag vælges i 2. Valgkres den agrarvenlige national-liberale Møller A. Wommelsdorf paa Munkmelle mer 13050 Stemmer imod 8725, som falder paa Socialdemokraten P. Michelsen. - I 4 Valgkres vælges den frisindede Dr. Leonhart i Kiel med 9620 Stemmer (hvoraf 817 danske) imod 9217 , som falder paa den national-liberale Kandidat, Landsretsraad Feddersen. Dr. Leonhart er saaledes sat igennem af danske Stemmer. 
18. Februar. Rigsretten i Leipzig ophæver den af Landsretten i Flensborg den 3. September 1906 fældede Dom, hvorved Journalist P. Simonsen ved "Flensborg Avis" idømtes 9 Maane. ders Fængsel for formentlig Fornærmelse mod Kaptejn Hennings i Bremen, og henviser Sagen til ny Behandling ved Landsretten i Altona. Rigsretten antager, at Forudsætningen for, at den tiltalte skulde være skyldig - at han havde vidst, at der endnu var nogle af de paagældende Officerer i Live, og saaledes havde haft en fornærmelig Hensigt - ikke er tilstrækkelig bevist.

20. Februar. "Hejmdal" meddeler, at de danske Landdagsmænd $i$ den prøjsiske Landdag atter har inbbragt deres Lovforslag oin en Fndring af Valgloven til Kresdagene. (Jf. 5. Marts 1906).

1. Marts. Overpræsident v. Dewitz fratræder sit Embede efter at have faaet sin paa Grund af Sygdom indgivne Afskedsbegæring bevilget. - I hans Sted tiltræder tidligere Landraad, Godsejer paa Bossee i Holsten, Detlev v. Bülow, Embedet som Overpræsident i Hertugdømmerne.

21. Marts. Ved et Møde i Forsamlingshuset i Brøns oprettes "Nordvestslesvigsk Landboforening", hvis Program er Fremhjælp af Gaard- og Husinandsbrug.

2. April. Paa et Møde i Vojens oprettes en Fælles-Afholdsforening for Nordslesvig.

8. April. Landsretten i Flensborg frikender Landmand P. Gadegaard paa Rødding Mark og Journalist J. Jensen i Aabenraa for at have fornærmet en Amtsretssekretær ved en i dal" offentliggjort Meddelelse om en Tørvelevering. Landsretsdirektør Jacobsen tager under Retsforhandlingen Anledning til at betegne det som begribeligt, naar Myndighederne ikke lader nogen Fortjeneste tilflyde dem, der ${ }_{n}$ vender sig agitatorisk imod Tyskland."

12. April. Kaadner P. Simonsen og Landmandssøn $P$. Petersen fra Taps udvises af den stedfortrædende Amtsforstander i Tyrstrup med 24 Timers Varsel, fordi de har været med til at lede nogle Gymnastikøvelser i Forsamlingshuset „Frej“ i Tyrstrup. 
16. April. Amtsforstarder Kosegarten sælger sin Ejendom "Vojensgaard " til Ejendomskommissionær J. H. Schmidt i Haderslev for ${ }^{1,}$ Million Mark uden Besætning.

3. Maj. Landsretten i Flensborg frikender Tandlæge J. Smith i Haderslev for Overtrædelse af Straffelovens $\$ 110$ ved at have opfordret til Ulydighed. Da nemlig flere Amtsforstandere har udstedt Forbud imod Gymnastikundervisning og Smith anser disse Forbud for ulovlige, har han i Bladet "Modersmaalet" offentlig opfordret til at være ulydig imod dem for paa den Maade at faa Spørgsmaalet afgjort ved Domstolene. Landsretten antager, at det ikke drejer sig om Opfordring til Ulydighed i Henhold til Straffelovens $\$ 110$.

7. Maj. "Hejmdal“ meddeler, at Myndighederne i Kliplev har forbudt Brugen af de gamle brogede Nationaldragter ved Opførelsen af de nordiske Folkedanse.

10. Maj. Et tysk Blad meddeler, at der hidindtil er blevet naturaliseret 1000 Optantbørn.

12. Maj. Forsamlingshuset i Hyrup indvies.

16. Mai. Bisidderretten i Haderslev stadfæster fem Politibøder paa hver $10 \mathrm{Mark}$, som fem Mænd fra Lert og Ørsted Kommuner, Moller Kiesby, Landmændene H. Jensen, P. Thielsen og H. J. Witt samt Forpagter Christiansen, i Foraaret er blevne ikendte for at have ovet grov Uorden ved, at de under Rigsdagsvalget i Valglokalet havde forlangt, at Stemmesed. lerne skulde blandes og at en Kontroler ved Valgurnen blev fjærnet.

27. Maj. Ved et Møde paa "Folkehjem“ i Aabenraa vedtager Repræsentanterne for 8 nordslesvigske Landboforeninger med tilsammen $3500 \mathrm{Med}$ lemmer atter at oprette en Fælleslandboforeniug Til Formand for denne vælges Gaardejer MI. Refslund Poulsen paa Skovgaard ved Aabenraa. Samtidig vedtages det at ansætte Landbrugskandidat $H$. Hansen fra Ringenæs som Fælleslandboforeningens Konsulent

30. Maj. Bisidderretten i Haderslev frikender Landbolsmændene J. Jepsen og $J$ Heinsvig fra Aarø, der er anklagede for, at de under et Ordskifte ved Rigsdagsvalget skal have fornær- 
met den fungerende Valgforstander, Landmand Hansen fra Aarø.

5. Juni. De to københavnske Skuespillere R. Neiiendam og J. Texière faar paa Amtsforstanderkontoret i Sønderhorg Meddelelse om, at de ikke maa holde Oplæsninger i Nordslesvig. De maa desuden ved deres Cnderskrift forpligte sig til at være ude af Landet inden 24 Timer, da de ellers vil blive udviste.

6. Juni. I den prøjsiske Landdag forhandles det af Landdagsmændene H. P. Hanssen og Julius Nielsen midt i Februar indbragte Lovforslag om Kreslovens Andring. - Landdagsmand Julius Nielsen anbefaler Lovforslaget under Henvisning til Ejendornsforholdene i de paagældende Amter, hvor gennemsnitlig kun 7 Procent af Grundejerne hører til de store Grundejeres Klasse, i Haderslev Amt endogsaa kun 1 Procent. - Den national-liberale Amtsretsraad Bachmann fra Haderslev taler imod Lovforslaget, idet han gør opmærksom paa, at det vilde skabe et dansk Flertal i nople af de nordslesvigske Ainter. - Huset vedtager imod Polakkernes, de frisindedes og Centrums Stemmer at gaa over til Dagsordenen. - Landdagsinand H. P. Hanssen bebuder derefter, at Lovforslaget atter vil fremkomme næste Aar.

9.-10. Juni. Det sjette danske Aarsmøde afholdes paa "Folkehjem" i Aabenraa. (Jf. „Sønderjydske Aarb." 1908, Side 84.)

15. Juni. Regeringspræsidenten i Slesvig ophæver Cdvisningsordren mod Kaadner P. Simonsen og Landmandssøn P. Petersen fra Taps. (Jf. 12. April). De faar dog kun Lov til i private Anliggender at overskride Grænsen, hvorimod de kan "vente deres øjeblikkelige fornyede Udvisning, saafremt de ved at meddele Gymnastikundervisning eller paa anden fremtrædende Maade optræder som Indbydere, Ledere eller Lærere ved Møder og derved igen falder til Besvær."

1. Juli. Landsretten i Flensborg frikender fem Mænd fra Lert og Ørsted Kommuner for under Rigsdagdvalget at have ovet grov Uorden i Valglokalet. (Jf. 16. Maj).

2. Juli. Overpræsidiet i Slesvig ophæver telegrafisk Udvisningsordrerne mod Gaardejerne C. og N. 
Finnemain, saa de endelig efter fem Aars Landflygtighed kan vende tilbage til Taarning.

3.-5. Juli. Det tyske Kejserpar hesøger det danske Kongepar paa Fredenshorg.

10. Juli. Bisidderretten i Norlborg idømmer Værten paa "Nørherredshus", P. Jensen, og Rentier Kl. Andersen i Nordborg henholdsvis 10 og 8 Dages Fængsel for paastaaet Mo dstand mod Statsmagten. De har nemlig en Aften i April Maaned forhindret en Politibetjent $i$ at trænge ind i Salen paa "Nørherredhus", hvor et privat Selskah var samlet med Koncertsangerinde Fru Hornemann fra Kobenhavn snin Grst, medeus Myndighederne stemplede denne Sammenkomst som et offentligt Møde.

12. Juli. Landbrugskauret for Hertugdanmerne holder sin 25 Plenarforsamling i Haderslev. - Ved en paafølyende Middag i "Borgerforeningen" holder Formanden, Grev Rantzau fra Rastorf, en politisk Tale, bvori han navnlig fremhrever Kravet om tysk Troskab i Grænselandene samt Selvhjielpens Sikkerhed i Modsætning til Statshjelpens. - Lidt senere udbringer Overpriesident $v$ Bülow et Leve for Nordslesvigerne: han roser den nordslesvigske Befolknings Flid og Dygtighed, dens Erbarhed og Sædelighed, dens Kundskabstran $r$ og alvorlige Stræetien, og han opfordrer Tyskerne til at vise denne Befolkning deres fulde Tillid, thi om end Sprog og Tilbojelighed er forskellige, er doy Naturen, de økonomiske Interesser og Afstamningen frelles; han slutter med, at Tyskerne er stærke og mægtige nok til at byde de darıske Nordslesvigere Broderkysset (senere rettet til Broderhaanden). - Umiddelhart derefter rejser Grev Rantzau sig atter og holder en endnu mere udpræget politisk Tale, hvori han serlig betoner, at de Landboforeninger, der staar i Forbindelse med Landbrugskamret, maa staa paa tysk national Grund, thi Kamret er et slesvig-holstensk Kammer, og at være slesvig-holstensk, det er at være tysk; enhver Landmand, der staar paa samme nationale Stanrlpunkt som Kamret, kan gøre Krav paa dets Hjælp, men hvem der ikke gør det, eksisterer ikke for Kamret. 
23. Juli. Af 69 nordslesvigske Præster indsendes til Overpræsidenten i Slesvig et Andragende om, at der i Skolerne maa blive indført to frivillige danske Sprogtimer oun Ugen.

21. Juli. Sønderborg Provstisynode vedtager med $44 \mathrm{imod}$ 18 Stemmer et af Aftægtsmand Jørgen Nielsen i Mjang stillet Forslag om hos Konsistoriet $i$ Kiel at andrage paa, at Overprixsidial-Anvisningen af 18 December 1888 delvis ophæves, og at der i de Skoler, hvor der endnu er dansk Religionsundervisning, gives Børnene mindst to Timers dansk Sprogundervisning om Ugen.

27. Juli. Provst Gottfriedsen i Nustrup modtager fra Overpræsident v. Bülow et Afslag paa det den 23. Juli af 69 nordslesvigske Præster indsendte Andragende om, at der $\mathrm{i}$ de nordslesvigske Skoler maa blive jndført to frivillige danske Sprogtimer oin Ugen. Afslaget begrundes med, at $n$ de herom ogsaa inden for den kongelige Statsregering gentagende stedfundne Overvejelser stedse har ført til det samme Resultat, ikke at forandre Sproganordningen af 18 . December 1888 i den af Dem ønskede Retning ", og Overpræsidenten anmoder derfor Præisterne om "nu at finde Dem i, at Afskaffelsen af den danske Sprogundervisning i Folkeskolen er en Kendsgerning, som ikke mere vil blive forandret."

31. Juli. Torninglen Provstisynode vedtager med alle mod tre Stemmer et af Provst Gottfriedsen stillet Forslag om at tage folgende Udtalelse til Protokols: "Vi beklager paa Kirkens og det religiøse Livs Vegne dybt, at de 69 Præsters Indstilling om dansk Sprogundervisning ikke er bleven tagen til Følge." Endvidere vedtager Synoden med alle imod to Stemmer følgende, af Pastor Matthiesen i Rødding stillede Forslag: „Tørninglen Provstisynode beder i Tillid det kongelige Konsistorium paa rette Sted og til rette Tid at ville arbejde hen til, at der $i$ de af Provstiets Folkeskoler, hvor der gives dansk Religionsundervisning, indføres to ugentlige danske Sprogtimer indenfor den normale Skoleplan for alle de Børn, hvis Forældre maatte onske en saadan Undervisning." 
Den officiøse „Norddeutsche Allgemeine Zeitung ${ }^{\text {" }}$ meddeler, at der indtil 15. Juli er blevet naturaliseret 2834 Optantbørn, hvilket efter Bladets Mening er tre Fjerdedele af allo Optantbørn. Desuden er der blevet naturaliseret 356 Optanter, hvoraf Halvdelen or Kvinder. Af danske Undersaatter, der er fødte i Kongeriget, er der blevet optaget 97 . Tilsammen er der saaledes siden 11. Januar blevet optaget 3287 Personer.

3. Avgust. Den tyske Forening holder Bestyrelsesmøde i Rødekro. Dr. Hahn meddeler, at han har været i Slesvig hos Overpræsident v. Bülow og faaet on Række Lofter af ham: en Eftergivenhed $i$ lighed med Finnemann-Sagens Ordning skulde ikke forekomme oftere, Optantspørgsmaalet skulde ikke blive løst, det hidtilværende Politistyre vilde blive opretholdt; endvidere vilde der blive bevilget Penge til Opkab af danske Ejendomme, til Ydelse af billige Laan, til Gratisophold paa tyske Højskoler o. a. m.

10. Angust. Den nordslesvigske Vælgerforenings Bestyrelse og Tilsynsraad offentliggør følgende Udtalelse: "Idet vi udtaler vor Paaskonnelse af Overpræsident v. Bülows Tilsagn om at møde den danske Befolkning i Nordslesvig med Tillid og venter, at han vil forvalte det hoje Embede, der er ham betroot, retfærdigt og upartisk, nedlægger vi en bestemt Indsigelse imod den af et fanatisk Agitationsudvalg forsøgte Ophidselse af det tyske Folk. Overfor de grove Usandheder, der i den senere Tid er blevet udspredt i Tyskland, erklærer vi : Den danske Befolkning i Nordslesvig udfolder ingen Løsrivelsesbestræbelser og driver ingen Boykotning. Den staar paa Forfatningens og de bestaaende Loves Grund og udfolder kun fuldtud lovlige Eestræbelser til Værn af sin nedarvede Nationalitet.

22. Avgust. Overlandsretten i Kiel stadfæster i Sagen mod fem Mænd fra Lert og Ørsted Kommuner den flensborgske Landsrets frifindende Dom. (Jf. 1. Juli og 16. Maj.)

Gaardejerne C. og N. Finnemann, Fader og Søn, faar deres Naturalisationsbeviser udleveret. (Jf. 2. Juli.) 
26. Avgust. Landsretten i Flensborg stadfæster den af Bisidderretten i Nordborg den 10 Juli fældede Dom, hvorved Værten paa "Nørherredhus", P. Jensen, og Rentier Klavs Andersen i Nordborg ikendtes henholdsvis $10 \mathrm{og} 8 \mathrm{Da}$ ges Fængsel for Modstand mod Statsmagten; Landsretten anser vedkommende private Sammenkomst for et politisk Møde, hvortil Politiet havde Adgang.

6. September. Bladet "Hejmdal" i Aabenraa udkommer i forstørret, syvspaltet Format.

Landsretten i Flensborg frikender Ungkarl Andreas Grau fra Bro, Mejerist H. Lorentzen fra Gramby og Redaktor E. Christiansen fra Flensborg for $i$ en Artikel i „Flensborg Avis" den 16. Marts at have fornærmet Degn og Skolelærer Bager i Ketting ved at meddele, at han i Skolen havde blandet Politik i Undervisningen og om de danske Foregangsmænd brugt grove Skældsord som "Danskerpak", "danske Hunde", "Løgneprofeter" og lignende. Baade Statsadvokaten og Retten indrømmede, at Sandhedsbeviset var blevet ført.

17. September. Haderslev Provstisynode vedtager med 46 af 65 Stemmer et af Pastor Tonnesen i Hoptrup stillet Forslag om at rette den samme Anmodning til Konsistoriet i Kiel, som Tørninglen Provstisynode den 31. Juli vedtog at indsende til Konsistoriet.

24. September. Landsretten i Altona idømmer Journalist P. Simonsen ved "Flensborg Avis" 4 Maaneders Fængsel for formentlig Fornærmelse mod Kaptejn Hennings i Bremen. (Jf. 18. Febr.) Retten antager, at det paaklagede Udtryk ( mensvoren $^{\alpha}$ ) i den paagældende Sammenhæng er fornærmeligt, og at den anklagede havde maattet regne med den Mulighed, at der endnu levede nogen af de omhandledo Officerer.

30. September. Det forbydes den danske Tryllekunstner Georg Kjeldsen at give Forestillinger i Nordslesvig.

1. Oktober. "Modersmaalet" i Haderslev kan fejre sit 25 Aars Jubilæum, idet Rladet blev oprettet den 1. Oktober 1882 af nuværende Teglværksejer Axel Sabroe. 
"Vestslesvigs Tidende" kan fejre sit 25 Aars Jubilæun, idet Redaktør P. Skovrøy i Tønder oprettede Bladet den 1. Oktober 1882. (I Juni 1885 blev "Vestslesvigs Tidende* forenet med ${ }_{n}$ Flensborg Avis ${ }^{4}$ og er siden da udkommet som en Særudgave af denne.)

Bladet "Den nordslesvigske Kirkesag", som hver fjortende Dag udgives af Frimenighedspræst Thade Petersen i Haderslev, begynder at udkomme.

4. Oktober. Forsamlingshuset i Fol indvies ved et Mode, hvori henved 200 Personer deltager.

8. Oktoher. Den nordslesvigske Vælgerforenings Bestyrelse og Tilsynsraad vedtager paa et Møde paa "Folkeljem" i Aabenraa følgende to Resolutioner:

I. Vælgerforeningens Bestyrelse og Tilsyusraad udtaler en skarp Misbilligelse af Redaktor Svenssons i „Dybbøl-Posten" fremsatte Mistænkeliggorelse af Beskyldninger imod Rigsdagsmand H. P. Hanssen. Efter at Sagen foreligger fuldt oplyst, viser $\mathrm{Sig}$ telserne sig tilmed aldeles uhjernlede. Rigsdagsmand Hanssen fortjener Vælgernes varmeste Tak for hans store Arbejde i Optantsagen, særlig ogsaa i den Finnemanske Sag.

II. Idet vi udtaler vor fulde Tilslutning til vore Repræsentanter, Rigsdagsmand $\mathrm{H}$. P. Hanssens og Landdagsmand Julius Nielsens Politik, bringer vi dem en varm Tak for deres trofaste Arbejde iblandt os og haaber, at de fremdeles $i$ en lang Aarrække maa faa Lykke og Held til at fortsætte Arbejdet for vor Folkesag. Vi tilsikrer dem endvidere al den Støtte, som vi er i Stand til at yde dem $i$ vor nationale Kamp.

20. Oktober. Paa et Møde i Graasten oprettes en FællesSangforening for Nordslesvig; der indmelder sig straks 12 Foreninger med 205 Medlemmer.

26. Oktober. Forsamlingshuset i Tyrsbøl indvies ved et talrig besøgt Møde.

31. Oktober. Bisidderretten i Haderslev forhandler en Privatklagesag, som Amtsforstander Kosegarten i Vojens har anlagt imod Redaktøren af "Schleswigsche Grenzpost"; K. Strackerjan, og Forretningsføreren ved Bladet, Uwo Schütze i Haderslev; for Fornærmelse. Efter 
Salget af "Vojensgaard" til en dansk Mand havde "Schleswigsche Grenzpost" nemlig bragt et Par Artikjer, hvorefter Amtsforstander Kosegarten sknlde staa i betydelig Gæll til Landdagsmand Julius Nielsen. Sagen ender med et Forlig, idet begge de tiltalte mer Beklagelse tager deres urigtige Paastande tilbage.

Bisidderretten i Haderslev idømmer Redaktøren af "Schleswigsche Grenzpost", K. Strackerjan, en Bøde paa 3 Mark, fordi han ikke har optaget en Berigtigelse, som „Haderslev Bank" har sendt ham vedrørende Advokat Ravns Studiepenge. Den anklagede undskylder sig for Retten med, at han har kastet Brevet i Brevkurven uden at aabne det, fordi han kunde tænke sig, hvad det indeholdt.

(j. November. Paa det tyske Kasermeskib „Blücher" ved Marinestationen Mørvig eksploderer en Dampkedel, hvorved 15 Mennesker dræhes eller dør af deres Saar, medens en Del forbrændes.' Ulykken skyldes Skødesløshed ved $\mathrm{Ke}$ delens Betjening.

18. November. Landsretten i Flensborg frikender tidligere Pastor Jakobsen, Bogholder Rabe og Købmand $\mathrm{Kr}$. Petersen i Skærbæk for strafbart Forhold vedrørende Kunstvæveskolen i Skærbæk. (Forseelse mod Konkursloven, falske Balancer o. s. v.) Den 27. Juni 1904 blev Pastor Jakabsen i samme Sag idømt 2 Maaneders Fængsel og 900 Mark i Bøde, medens de to andre fik 1 Maaneds Fængsel og 600 Mark i Bøde; men det or lykkedes dem at faa Straffens Afsoning udsat og Sagen gen-. optagen til ny Forhandling.

20. November. "Flensburger Nachrichten" meddeler, at tidligere Pastor Jakobsen i Skærbæk er bleven udnævnt til Sognepræst for den protestantiske. Menighed i Arco, en lille By i Tyrol: han skal allerede holde sin Tiltrædelsesprædiken den 24. November.

Forsamlingshuset i Hygum indvies ved et Møde, hvori der deltager henved 400 Personer.

8. December. De nordslesvigske Frimeningheder holder deres Aarsmøde i Sundeved.

Jørgen Eriksen fra Oksbol paa Als indvies som Præst ved Frimenighedskirken i Sundeved. 
9. December. Rigsretten i Leipzig forkaster den af Landsretten i Flensborg den 3. Maj fældede Dom, hvorved Tandlæge J. Smith fra Haderslev frifandtes for at have overtraadt $\S 110$ i Straffeloven ved at opfordre til Ulydighed, og viser Sagen tilbage til ny Behandling ved Landsretten. Rigsretten udtaler, at Landsrettan i Flensborg fejlagtig har antaget, at de paagældende Gymnastikforbud ikke var $\emptyset$ vrigheds-Anordninger.

"Cdvalg for kristelig Virksombed i Nordslesvig" holder Aarsmøde paa "Nørherredhus" i Nordborg. Udvalget har $i$ det sidste Aar ladet afholde 102 Nøder rundt omkring i Nordslesvig og det har nu ialt ladet omkring ved 30 Sygeplejersker uddanne.

10. December. I den tyske Rigsdag taler Rigsdagsmand H. P. Hanssen imod Tvangshestemmelserne i den foreslaaede Rigs - Forenings- og Forsamlingslov. Han fremhæver, at $\S 7 \mathrm{er}$ en Undtagelsesbestemmelse af værste Slags; den vil paa en unyttig Maade skærpe Mlodsætningerne i Nordslesvig, og man vil ikke alene føle en saadan Bestemmelse som en ungdvendig Haardhed, men tillige som en brutal Uretfierdighed. Talen modtages med livligt Bifald fra Husets Venstre.

15. December. Forsamlingshuset "Møgeltanderhus“ i Møgeltonder indvies ved et Møde, hvorved der er rigelig 300 Mænd og Kvinder til Stede.

17. December. Overpræsident v. Bülow nægter den norske Skuespillerinde Johanne Dybvad Tilladelse til at opfore et Par af Henrik Ibsens Skuespil i Nordslesvig.

19. December. Bisidderretten i Haderslev idømmer Byens Borgmester, Dr. jur. Schindelhauer, en Bøde paa 100 Mark for at have fornærmet Redaktorerne af "Nodersmaalet ${ }^{4}, \mathrm{~N}$. Svendsen og N. Petersen, ved en Aften sidst i Oktober Maaned i en Frugthandlers Butik paa Søndertorv at have ytret sin Forbavselse over, at Frugthandleren holdt en saadan ,Schimpf-, Schund- und Schweinezeitung" som det danske "Modersmaalet". Den dømte Borgmester bebuder under Forhandlingen, at han vil indanke Sagen og eventuelt føre den helt op. til øverste Instans. 
20. December. Fru Bolette K. Krüger, født Thomsen, Enke efter afdøde Rigsdagsmand H. A. Krüger i Bevtoft, afgaar efter lang Tids Svagelighed ved Døden $i$ en Alder af 87 Aar.

28. December. Forsamlingshuset i Genner indvies ved et Møde, hvori der deltager 250 Personer.

Forsamlingshuset i Bredebro indvies ved et Møde, hvori der deltager omkring ved 300 Personer.

N. A. 


\section{"Sønderjydske Aarbøger" ulgrivne "tf}

\section{*. P. Fanssen-Norremolle, P. Skau og Nikolaj findersen}

begyndte at udkomme isse on har siden i "ll Rirkki" forskellige Bidrag skildrot Silesvigs Historie, Laud, Folk og Minder og har i politiske og statistiske Oversigter belyst Nordshesvigernes Kamu for Bavarelsen af dansk Sprogr og Kultur.

,Sonderjydske Aarboger" vil sm hidtil hellandle allo nordslusvigske sporgsmaal i videste ()mfange, Historie og Politik, Sprour on Folkemindir, Naturforhold or Landokonomi. De vil desulen loringer Skildringer af andro Nationalitotskampe i Fortid og $\mathrm{Nutid}$ og Droftelse af saalanne Forhold, der direkte (eller indirekte staar i Forbindelse dermed.

,Sonderjydske Aarbogerbs udkommer to ( iange a arligt i Harfter paa tilsammen omtr. 20 Ark. Subskription modtages i allo Boglader i Slesvigr, Daumatrk, Norge ng Srerigo og i (iyldendalske Moghandel, Hovedkommissionen for de tre nordiske Lande. Prisen er 4 Kroner Aargangen; for Mrdlemmer af danskr Foreninger i Nordslesvig 3 Mark.

\section{Indhold af I. Halvbind 1908.}

Konventionen af 11. Januar 1907. Forhandlin-

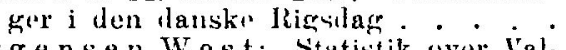

Fr. J ïrgensen Wrst: Ftatistik over Val-

Side 134 grene til den tyskr Kigsilag i 1., 2 or 4. slinvigrske Vulgkrids 1871 1907, med sixrrigrt Honsyn til de sidste Vialg 19()$\left.^{6}\right)-117$.

Thade Peterson: Det danske Aarsmode 1907

J. B. H б y er: De sproglige og national, Tilstande: pua Mollimslesvigs Hopdrrys Dagshistorie ved det 2(). Aarhundredes Begyndelst:

Ansvarharende: Nikolaj Andersen, Aahenrua. 